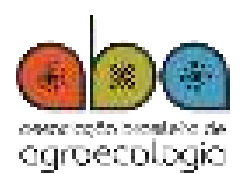

ISSN: $1980-9735$

DOI: $10.33240 /$ rba.v15i2.23113

Vol. $15 \mid$ NNo. $^{0} . \mid$ p. $81-85 \mid 2020$

NOTA AGROECOLÓGICA

\title{
AS INTERFACES E SINERGISMOS ENTRE A GROECOLOGIA E ECOFEMINISMO PODEM IMPULSIONAR A SUSTENTABILIDADE?
}

\author{
Can interfaces and synergism between agroecology and \\ ecofeminism improve sustainability?
}

Mônica de Sousa Alves' e Alexandre Túlio Amaral Nascimento²

1 Mestranda em Ciências Ambientais pela Universidade do Estado de Minas Gerais (UEMG). E-mail:

monicaalves.jornalista@gmail.com.

${ }^{2}$ Doutor em Ecologia, Conservação e

Manejo da Vida Silvestre pela Universidade Federal de Minas Gerais (UFMG); professor da Universidade do Estado de Minas Gerais (UEMG). E-mail:

alexandre.nascimento@uemg.br.

Recebido em: 03/10/2019

Aceito para publicação em: 10/03/2020

Correspondência para:

monicaalves.jornalista@gmail.com

\section{RESUMO}

Este estudo apresenta perspectivas da Agroecologia e do Ecofeminismo, analisando a inter-relação entre os dois movimentos nas propostas de resistência à lógica patriarcal e de luta pela sustentabilidade. Perceberam-se sinergismos que contribuem para o empoderamento das mulheres e as discussões da problemática ambiental. Entretanto, estudos que investiguem in loco as interfaces entre Ecofeminismo e Agroecologia são escassos e demandam maiores esforços.

Palavras-chave: Agroecologia. Ecofeminismo. Gênero. Sustentabilidade.

\section{ABSTRACT}

This study presents perspectives of Agroecology and Ecofeminism, analyzing the interrelationship between the two movements in the proposals of resistance to patriarchal logic and the struggle for sustainability. Synergies that contribute to women's empowerment and discussions of environmental issues were noticed. However, studies that investigate in loco the interfaces between Ecofeminism and Agroecology are scarce and require greater efforts.

Keywords: Agroecology. Ecofeminism. Gender. Sustainability. 
Com a constituição do Estado, da propriedade privada e da família consanguínea, consolida-se a lógica patriarcal e capitalista, em que tanto a mulher quanto a natureza são objetos de exploração e domínio (SILIPRANDI, 2015). Há, portanto, histórica opressão e sobrepujança do masculino sobre o feminino.

Se essa relação hierarquizada entre homens e mulheres é latente em toda sociedade, no meio rural ela é ainda mais perversa e silenciosa. De acordo com o relatório Terrenos da Desigualdade: Terra, Agricultura e Desigualdades no Brasil Rural, "são os homens que controlam a maior parte dos estabelecimentos rurais e estão à frente dos imóveis com maior área: eles possuem $87,32 \%$ de todos estabelecimentos, que representam $94,5 \%$ de todas as áreas rurais brasileiras" (OXFAM BRASIL, 2016). Entretanto, isso não significa que as mulheres estejam fora do processo do cultivo agrícola e extrativista. Pelo contrário, além das tarefas domésticas, elas estão engajadas em, praticamente, todas as atividades produtivas (GARCIA, 2012), embora tenham suas funções classificadas como de ajudantes e, na maioria das vezes, não sejam remuneradas (PACHECO, 2009).

As lutas contra esse sistema de desigualdade de gênero no campo, que perpassa pela divisão sexual do trabalho, têm pautado movimentos de diferentes esferas sociais e identitárias. A Agroecologia é um desses movimentos emergentes que, no decorrer das duas últimas décadas, além da concepção de agricultura mais sustentável, propõe uma nova construção social, que se fundamenta na relação de respeito entre homens e mulheres. Por respeito, entende-se espaços iguais (de fala, participação e decisão, p.ex.), rendimentos iguais, poder compartilhado e resistência a qualquer tipo de violência de gênero e ao sexismo (LIMA e JESUS, 2017).

O combate à opressão e à violência contra as mulheres e o questionamento da divisão sexual do trabalho são considerados elementos estruturantes da Agroecologia como ciência, movimento e prática (ASSOCIAÇÃO BRASILEIRA DE AGROECOLOGIA, 2017). Segundo Siliprandi (2009), a Agroecologia não pode cumprir seus propósitos se não incorporar as questões da subordinação das mulheres rurais, agricultoras e camponesas. Para Lima e Jesus (2017), seria incoerente se a proposta de respeito e solidariedade aos princípios da natureza do movimento agroecológico não envolvessem, também, a luta das mulheres contra a imposição do patriarcado.

Entretanto, fazer Agroecologia na amplitude de um novo modelo social não é tarefa simples, considerando que a opressão e violência contra as mulheres são ainda mais arraigadas no campo. Por isso, a Agroecologia precisa dos movimentos feministas, somando forças pelo empoderamento das mulheres perante as relações de submissão e exploração em que vivem (GARCIA, 2012).

Diante de muitas ações, ondas e correntes feministas, a correlação entre os princípios da Agroecologia com o Ecofeminismo merece atenção, por se tratar de movimentos que incorporam a luta de emancipação das mulheres às discussões acerca da problemática ambiental. Esta nota agroecológica analisa de que forma a Agroecologia e o Ecofeminismo se inter-relacionam na resistência e oposição à lógica patriarcal e se convergem em seus propósitos de luta por um novo paradigma de relação entre ser humano e natureza. Ainda, discute-se como essas ciências e movimentos sociais se complementam em um novo paradigma sociocultural fundamentado nos princípios da sustentabilidade, equidade social e interdependência.

Para compreender as interfaces entre Agroecologia e Ecofeminismo, é importante evocar a história do Movimento Agroecológico na década de 1930, pelos primeiros diálogos entre a Agronomia, Zoologia, Botânica e Fisiologia Vegetal (JACOB, 2016). Entretanto, foi na década de 1980 que a agroecologia se popularizou na América Latina, como resposta à modernização conservadora e propondo enfrentar a crise ecológica, bem como os problemas ambientais e sociais com manejo sustentável da natureza.

Miguel Altieri (2002), um dos principais estudiosos da Agroecologia na América Latina, relata que, na segunda metade do século XX, houve uma mudança no conceito da Agroecologia com a introdução da terminologia agroecossistema. Para Altieri (2002), os agroecossistemas podem ser definidos como configurações próprias de cada região, resultantes das variações locais do clima, solo e biodiversidade, assim como das relações econômicas, da estrutura social e da história. A partir desse conceito, de acordo com o autor, a Agroecologia passou a ser compreendida como ciência ou disciplina 
"que norteia princípios, conceitos e metodologias para se estudar, analisar, dirigir, desenhar e avaliar agroecossistemas, com o propósito de permitir a implantação e o desenvolvimento de formas sustentáveis de agricultura" (ALTIERI, 2004).

No Brasil, o debate agroecológico começou com os movimentos oposicionistas ao processo de mecanização e modernização da agricultura tradicional. Propagou-se com a discussão das consequências sociais da concentração de terra e da precarização das relações do trabalho e do êxodo rural (FERREIRA e MATTOS, 2017).

Nos anos 2000, por influência da escola europeia, a Agroecologia, além do técnico-agronômico, incorpora os olhares social, econômico, cultural e político. Segundo Pacheco (2014), a partir daí a Agroecologia agregou em seus princípios as lutas pela igualdade de gêneros e pela divisão sexual do trabalho nas atividades agrícolas de forma justa e igualitária.

Pensar o papel da mulher na Agroecologia implica em um retorno histórico para elucidar o seu protagonismo no surgimento da agricultura. Segundo Garcia (2012), no Paleolítico, quando o ser humano ainda vivia como nômade, os homens exerciam as funções de caçadores de grandes animais, enquanto as mulheres saíam em busca de vegetais comestíveis, embora contribuíssem também na caça de animais de pequeno porte. Após as colheitas, elas se reuniam para separar sementes que, em seguida, eram trituradas para produção de farinha. Nessa atividade, elas começaram a perceber que próximo às suas moendas brotava nova vegetação. Assim, surge a agricultura, pelo olhar observador das mulheres de que as plantas nascem das sementes. Logo, elas entenderam que se produzia mais quando as sementes eram mais vistosas e, assim, também protagonizaram as primeiras seleções naturais de sementes e raízes (GARCIA, 2012). Esse conhecimento milenar das mulheres ganha espaço na contemporaneidade pela Agroecologia, que se fundamenta, de mesma maneira, resgate e valorização do conhecimento ancestral.

Ao iluminar o papel relevante da mulher no pioneirismo do cultivo agrícola mais sustentável, passado de geração para geração, a Agroecologia sobrepõe-se aos princípios do Ecofeminismo, o qual "sugere a existência de uma estreita relação entre e a luta pela preservação da natureza e a emancipação das mulheres" (GARCIA, 2012). Esse fundamento pautou as primeiras manifestações ecofeministas na década de 1970, que iniciaram em uma mobilização de resistência "aos impactos negativos do desenvolvimento humano, a partir de uma perspectiva relacional entre humano, natureza e gênero" (LIMA e JESUS, 2017).

Considerado uma das correntes mais radicais dos movimentos feministas (GARCIA, 2012), o Ecofeminismo se propôs "a desestabilizar a separação entre natureza e cultura e a hierarquia entre os sexos" (GARCIA, 2012). Nessa linha combativa, o Ecofeminismo se consolidou no enfrentamento às relações opressivas e aos mecanismos de poder que estão por trás do sexismo, do racismo e da postura irresponsável da humanidade para com o meio ambiente.

O marco da corrente Ecofeminista foi a publicação do documento "Le Feminisme ou La Mort", da francesa Françoise D'Eaubonne, no ano de 1974. A publicação saiu em defesa "de uma proposta claramente feminina para os problemas ambientais [...]" (SILIPRANDI, 2015). No texto, D'Eaubonne apontava um tripé para a crise planetária: superlotação populacional, devastação da natureza e dominação masculina (PULEO, 2002).

O Ecofeminismo foi ganhando adesão no mundo em ações emblemáticas. Uma dessas iniciativas aconteceu na Índia, na década de 1970. O Movimento Chipko (palavra hindu que significa "agarrar") nasceu da união de um grupo de 30 mulheres de 17 comunidades de Mandal, que conseguiu impedir o corte de árvores que protegiam uma bacia hidrográfica no Bosque Garhwal. Ao invés de armas, elas utilizaram o abraço, o que deu nome à ação de "abraço na árvore". Essas mulheres conseguiram salvar 300 árvores de freixo.

Na sua expansão pelo mundo, o Ecofeminismo foi se divergindo e se complementando em três correntes principais: a Clássica (Essencialista), a Pré-Colonial (Espiritualista) e a Construtivista. A corrente Clássica, na visão de Puleo (2014), parte do pressuposto que homens e mulheres têm essências opostas. As mulheres se caracterizam com atitudes mais maternais e pacifistas e os homens tendem à destruição e competição. Nesse contexto, compreende-se que as mulheres carregam em sua essência 
uma relação com a natureza de preservação e cuidado. Esse pensamento tem fundamentações no dualismo criticado por alguns movimentos feministas, no entanto, ele coloca essas diferenças em favor da mulher, em afirmação identitária que busca revalorizar os âmbitos considerados femininos (PULEO, 2014).

A corrente Pré-colonial se expandiu como um movimento de oposição ao antropocentrismo das religiões dominantes, ao resgatar crenças místico-populares de deusas representantes da natureza e do feminino (PULEO, 2014). A defesa dessa corrente inclui a paz e a segurança global na busca por sociedades livres de violência, com tecnologias amigáveis à natureza, além de economias sustentáveis e respeitosas em relação às regiões e suas culturas (SILIPRANDI, 2015). Essa corrente, que tem na indiana Vandana Shiva uma das suas principais precursoras, critica o desenvolvimento ocidental - que coloniza, promove desigualdades, explora a natureza e as populações marginalizadas. Dessa linha advém a perspectiva de promoção de sociedades ativas e geradoras de energias criativas e não violentas e ameaçadoras, não se tratando, portanto, de demonizar o homem, mas sim de libertar as mulheres (SILIPRANDI, 2015).

Essas duas primeiras vertentes do Ecofeminismo são alvos de críticas pelos seus aspectos essencialistas, embasados nas premissas de que todas as mulheres teriam as mesmas características, decorrentes de atributos biológicos relacionados à maternidade. Isso as tornariam mais propensas ao cuidado, à docilidade e não agressividade (SILIPRANDI, 2015). Contrapondo a essa premissa essencialista, surgiu a corrente do Ecofeminismo Construtivista, que propõe que ambiente e gênero sejam encarados em sua realidade material e em suas formas específicas de interação, considerando distribuições de poder baseadas em gênero, classe, raças e etnias (GARCIA, 2012).

Pela corrente Construtivista, a perspectiva ecofeminista tem o potencial não somente de integrar a crítica feminista com a crítica ecológica, mas de ajudar a refletir sobre a criação da identidade humana, que legitima o domínio e que teria conduzido a atual civilização à crise autodestrutiva e ao ecocídio (PULEO, 2002). O Ecofeminismo Construtivista propõe "um pensamento crítico que postule a igualdade entre os gêneros e a autonomia das mulheres, além disso, que seja intercultural e afirme a unidade e continuidade humano-natureza" (SILIPRANDI, 2015).

Conforme Ferreira (2017), as três correntes do Ecofeminismo têm um ponto comum: a busca pela construção de uma nova sociedade mais cooperativa e de uma renovadora consciência cultural e ontológica. Nessa proposta, o poder da competição é substituído pelas relações mútuas (FERREIRA, 2017). De acordo com o autor, a filosofia Ecofeminista se contrapõe à perspectiva histórica e antropológica da dominação masculina e na visão de que a natureza é separada do social e do humano. Nessa sociedade patriarcal, segundo o pesquisador, propriedade, terra, natureza, escravos e mulheres se tornam objetos a serem domesticados e dominados. Segundo Ferreira (2017), esse movimento veio para substituir todos os símbolos patriarcais por conceitos de harmonia e igualdade, onde nada é para ser explorado ou controlado, mas sim para se construir uma energia conjunta. Dessa forma, ao relacionar cultura e natureza, segundo o pesquisador, o Ecofeminismo busca incutir nas mulheres a valorização de sua identidade, da sua força de trabalho e da sua representatividade social, por meio de uma construção fundamentada no respeito e preservação de todas as manifestações de vida.

O Ecofeminismo, com base nas suas principais referências teóricas, propõe mudanças afins aos princípios propostos pela Agroecologia: de equilíbrio e equidade entre espécimes agrícolas, homens e mulheres, e entre ser humano e natureza. Da mesma forma que o Ecofeminismo defende que as relações de poder levam à desumanização e destruição do planeta, a Agroecologia parte da compreensão sistêmica de um paradigma agrícola que não exclui, respeita os saberes tradicionais, os princípios ecológicos e é construído em espaços socialmente justos, harmônicos e igualitários.

Ecofeminismo e Agroecologia convergem no enfrentamento ao sistema machista que invisibiliza e oprime a mulher, que se reproduz no sistema de dominação e de destruição da natureza e da vida pelo ser humano. Também, se inter-relacionam nas contestações do efeito destrutivo das construções ideológicas de gênero e na relação de exploração predatória da natureza. A proposta comum é uma renovação na forma de existir e perceber a natureza e de se posicionar diante da vida, sem exploração e opressão, entendendo que devem caminhar juntas as lutas pelo empoderamento da mulher e pela 
reparação e cuidado dos ecossistemas que sustentam a vida, inclusive a sociedade humana e sua economia.

Nesse contexto, é possível afirmar que os sinergismos entre os movimentos agroecológicos e ecofeministas podem contribuir para que aconteçam as mudanças profundas, demandadas pela sustentabilidade. O Ecofeminismo leva a pressupor que as mulheres podem alavancar a produção agroecológica, desde que haja condições de igualdade de gênero e acesso às oportunidades. Assim, o protagonismo feminino no campo contribuiria para os propósitos emancipatórios, de equidade social e para a construção de uma relação de interdependência com a natureza.

Pesquisas e estudos que verifiquem essas hipóteses e busquem compreender as interfaces entre Ecofeminismo e Agroecologia in loco ainda são escassos e demandam maiores esforços. Avanços nesse diálogo entre esses dois movimentos podem apontar caminhos para a construção conjunta de um novo paradigma civilizatório, fundamentado em valores éticos e de cuidado, que nos conduza à uma sociedade consciente e praticante dos princípios de sustentabilidade, sem hierarquização dos sexos e preceitos de gênero.

\section{Referências}

ALTIERI, M. Agroecologia: bases científicas para uma agricultura sustentável. Guaíba: Agropecuária, AS-PTA, 2002, 592p.

ALTIERI, M. Agroecologia: a dinâmica produtiva da agricultura sustentável. 4.ed. - Porto Alegre: Editora UFRGS 2004, 120p.

ABA - Associação Brasileira de Agroecologia, Carta Agroecológica do Cerrado, 2017. Disponível em: https://abaAgroecologia.org.br/wp-content/uploads/2017/09/Carta-Politica-do-Cerrado-ABA-Agroecologia-1.pdf. Acesso em: 27 set. 2019.

FERREIRA, F.P.M. Corrente do Ecofeminismo propõe fim da sociedade patriarcal. Jornal Poiésis - Literatura, Pensamento \& Arte. e. 134, p.2, 2017.

FERREIRA, A.P.L. MATTOS, L.C. Convergências e divergências entre Feminismo e Agroecologia. Revista Ciência e Cultura, São Paulo, V. 69, n.2, p.38-42, abr./jul. 2017.

GARCIA, L. Meio Ambiente e Gênero. São Paulo: Senac, 2012, 219p.

JACOB, L.B. Agroecologia na Universidade. Entre vozes e Silenciamentos. Curitiba: Ed. Appris, 2016, 209p.

LIMA, M.M.T.; JESUS, V.B. Questões sobre gênero e tecnologia na construção da Agroecologia. Scientiae Studia, v. 15, n.1, p.73-96, 2017.

OXFAM, BRASIL. Relatório Terrenos da Desigualdade Terra, Agricultura e Desigualdades no Brasil Rural. Disponível em: https://oxfam.org.br/projetos/terrenos-da-desigualdade-terra-agricultura-e-desigualdade-nobrasil-rural/ . Acesso em: 27 set. 2019.

PACHECO, M.E. Os caminhos das mudanças na construção da Agroecologia pelas mulheres. Revista Agriculturas, Rio de Janeiro, RJ, v. 6, n. 4, p.4-8, dez, 2009.

PACHECO, M.E. Agroecologia e o fornecimento de alimentos. São Paulo, Canal Futura, 29 jul. 2014. Entrevista à jornalista Amelia Gonzalez.

PULEO, A.H. Feminismo y ecologia: Um repaso a las diversas corrientes del ecofeminismo. El Ecologista, Madrid: Verano, no 31, p. 36-39, 2002.

PULEO, A.H. Ecofeminismo para otro mundo posible. Ediciones Cátedra, 2014, 448p.

SILIPRANDI, E. Mulheres e Agroecologia: a construção de novos sujeitos políticos na agricultura familiar. 2009. 291f. Tese (Doutorado em Desenvolvimento Sustentável) - Centro de Desenvolvimento Sustentável da Universidade de Brasília, Brasília, 2009.

SILIPRANDI, E. Mulheres e Agroecologia: transformando o campo, as florestas e as pessoas. Rio de Janeiro: Ed. UFRJ, 2015. 356p. 